\title{
Desigualdade da distribuição da renda no Brasil: \\ a contribuição de aposentadorias e pensões e de outras parcelas do rendimento domiciliar per capita ${ }^{1}$
}

\author{
Rodolfo Hoffmann ${ }^{2}$
}

\begin{abstract}
Resumo
Inicialmente são discutidos problemas metodológicos relacionados com a mensuração da progressividade ou regressividade de uma parcela da renda, ou seja, da sua contribuição para reduzir ou acentuar a desigualdade da distribuição da renda. Em seguida, os dados da Pesquisa Nacional por Amostra de Domicílios (PNAD) de 2007 são usados para analisar a distribuição do rendimento domiciliar per capita no Brasil, verificando como o rendimento do trabalho (de militares e funcionários públicos, de outros empregados, dos conta-própria e dos empregadores), as aposentadorias e pensões, o rendimento de aluguéis e outras parcelas do rendimento afetam a desigualdade de renda no Brasil. Finalmente, é analisada a contribuição dessas parcelas para a redução do índice de Gini da distribuição do rendimento domiciliar per capita (RDPC) no Brasil entre 2001 e 2007. Verifica-se que quase 50\% dessa redução no índice de Gini está associada a modificações no rendimento dos salários no setor privado. Outra conclusão é a de que as aposentadorias e pensões oficiais são regressivas, ainda que as alterações ocorridas nos últimos anos tenham contribuído para a redução do índice de Gini.
\end{abstract}

Palavras-chave: Desigualdade; Progressividade; Decomposição do índice de Gini; Distribuição da renda - Brasil - 2007.

\section{Abstract \\ Inequality of income distribution in Brazil: the contribution of pensions and of other components of per capita household income}

The paper starts with a discussion of methodological problems that arise when measuring whether a component of total income is progressive or regressive, v.g., whether such component contributes to reduce or to increase the inequality of the income distribution. Next, it examines the data of the last National Sample Survey of Households of Brazil (PNAD, 2007), to update the analysis of the distribution of per capita household income in Brazil and verify how income from work (of the military and civil servants, of other employees, of self-employed and of employers), from pensions, from rents and from other components of income influence income inequality in Brazil. Finally, it examines how each of these components contributed to reduce the Gini index of the distribution of per capita household income in Brazil in the period 2001-2007. It becomes evident that about 50\% of such reduction in the Gini index is associated with changes in the income component "wages in the private sector". Another conclusion is that the pensions provided by the official system are regressive, even though changes in the income from pensions in the last years have contributed to the reduction of the Gini index.

Key words: Inequality; Progressivity; Gini index decomposition by factor components; Brazil Income distribution - 2007.

JEL D31, D33.

(1) Trabalho recebido em dezembro de 2008 e aprovado em fevereiro de 2009.

(2) Professor do Instituto de Economia da Universidade Estadual de Campinas (Unicamp. IE), Campinas, SP, Brasil. O autor contou com apoio do CNPq e agradece a Fernando Gaiger Silveira e Celia Lessa Kerstenetzky pela leitura crítica de versão preliminar do texto. E-mail: < rhoffman@eco.unicamp.br>. 


\section{Introdução}

De acordo com os dados da Pesquisa Nacional por Amostra de Domicílios (PNAD), a desigualdade da distribuição de renda no Brasil sofreu substancial redução nos últimos anos, mas continua sendo muito elevada em comparação com outros países (IPEA, 2008a).

O rendimento de aposentadorias e pensões é uma parcela importante dos rendimentos declarados, tendo aumentado de 15,2\% em 1997 para 18,5\% em 2001 e $19,8 \%$ em 2003 e 2005. Na PNAD de 2007, as aposentadorias e pensões representam $19,4 \%$ da renda total dos domicílios. As aposentadorias e pensões pagas por instituto de previdência ou pelo governo são as predominantes, representando $14,1 \%$ de toda a renda declarada dos domicílios em 1997; 17,1\% em 2001; 18,5\% em 2003 e 17,9\% em 2007.

Há controvérsia sobre a contribuição das aposentadorias e pensões para a desigualdade da distribuição da renda no Brasil. Alguns trabalhos indicam que aposentadorias e pensões, no Brasil, contribuem para reforçar a desigualdade [Hoffmann (2003), Hoffmann e Leone (2004), Ferreira (2006) e Nicholson (2007)], enquanto outros indicam que aposentadorias e pensões contribuem para reduzir a desigualdade (Dedecca et al., 2007 e IPEA, 2008b). Cabe mencionar, também, os trabalhos que procuram destacar os efeitos das aposentadorias e pensões iguais a um salário mínimo (Soares et al., 2007 e Hoffmann, 2007b), cujo efeito é claramente progressivo (contribuem para reduzir a desigualdade).

Neste artigo, os dados da PNAD de 2007 são usados para atualizar a análise da contribuição de várias parcelas do rendimento domiciliar per capita (RDPC) para a desigualdade total e discutir algumas questões metodológicas relativas à caracterização de uma parcela como progressiva ou regressiva.

Finalmente, é analisada a contribuição dessas parcelas do rendimento familiar para as mudanças no índice de Gini da distribuição do RDPC no Brasil, no período 20012007, dando continuidade a diversos trabalhos sobre esse tema publicados em Barros; Foguel e Ulyssea (2006, 2007).

\section{Decomposição do índice de Gini e a medida da progressividade de uma parcela da renda}

Nesta seção apresenta-se a metodologia que permite determinar as frações do índice de Gini associadas a diferentes parcelas da renda para, em seguida, mostrar como se pode mensurar o grau de progressividade ou regressividade de uma parcela, isto é, avaliar em que medida uma parcela contribui para reduzir ou para acentuar o grau de desigualdade da distribuição da renda.

Seja $x_{i}$ a renda da $i$-ésima pessoa em uma população com $n$ pessoas. Admite-se que as rendas estão ordenadas de maneira que

$$
x_{1} \leq x_{2} \leq \ldots \leq x_{n}
$$


A renda média é

$$
\mu=\frac{1}{n} \sum_{i=1}^{n} x_{i}
$$

Agregando as pessoas da mais pobre até a $i$-ésima posição na série (1), a proporção acumulada da população é

$$
p_{i}=\frac{i}{n}
$$

e a respectiva proporção acumulada da renda é

$$
\Phi_{i}=\frac{1}{n \mu} \sum_{j=1}^{i} x_{j}
$$

Sabe-se que a curva de Lorenz mostra como $\Phi_{i}$ varia em função de $p_{i}$. Admitindo que $x_{i} \geq 0$ e sendo $\beta$ a área entre a curva de Lorenz e o eixo das abscissas $\left(p_{i}\right)$, o índice de Gini pode ser definido como

$$
G=1-2 \beta
$$

Pode-se demonstrar que o mesmo índice é dado por

$$
G=\frac{2}{n \mu} \operatorname{cov}\left(i, x_{i}\right)
$$

Considere-se, em seguida, que a renda $x_{i}$ é formada por $k$ parcelas, de maneira que

$$
x_{i}=\sum_{h=1}^{k} x_{h i}
$$

com $x_{h i}$ representando o valor da $h$-ésima parcela da renda da $i$-ésima pessoa.

A média da $h$-ésima parcela é

$$
\mu_{h}=\frac{1}{n} \sum_{i=1}^{n} x_{h i}
$$

e a proporção acumulada do total dessa parcela até a $i$-ésima pessoa na série (1) é

$$
\Phi_{h i}=\frac{1}{n \mu_{h}} \sum_{j=1}^{i} x_{h j}
$$

Analogamente à definição da curva de Lorenz, denomina-se curva de concentração da $h$-ésima parcela a curva que mostra como $\Phi_{h i}$ varia em função de $p_{i}$. Cabe ressaltar que na construção da curva de concentração de $x_{h i}$ é utilizada a ordenação dos $x_{i}$ (e não a ordenação dos $x_{h i}$, que pode ser diferente). 
Admitindo que $x_{h i} \geq 0$ e sendo $\beta_{h}$ a área entre a curva de concentração de $x_{h i}$ e o eixo das abscissas $\left(p_{i}\right)$, a respectiva razão de concentração é definida como

$$
C_{h}=1-2 \beta_{h}
$$

Note-se a semelhança entre (5) e (10). Analogamente a (6), pode-se demonstrar que

$$
C_{h}=\frac{2}{n \mu_{h}} \operatorname{cov}\left(i, x_{h i}\right)
$$

Verifica-se que $-1+\frac{1}{n} \leq C_{h} \leq 1+\frac{1}{n}$.

A participação da $h$-ésima parcela na renda total é

$$
\varphi_{h}=\frac{\sum_{i=1}^{n} x_{h i}}{\sum_{i=1}^{n} x_{i}}=\frac{\mu_{h}}{\mu}
$$

Pode-se demonstrar que o índice de Gini é a seguinte média ponderada das razões de concentração:

$$
G=\sum_{h=1}^{k} \varphi_{h} C_{h}
$$

Como $\sum \varphi_{h}=1$, pode-se escrever

$$
G=G-\sum_{h=1}^{k} \varphi_{h}\left(G-C_{h}\right)
$$

Com $\varphi_{h}>0$, o sinal de $G-C_{h}$ é que determina se a parcela contribui para reduzir ou aumentar o valor do índice de Gini. Se $C_{h}<G$, a parcela $x_{h i}$ está contribuindo para reduzir o índice de Gini. Se $C_{h}>G$, a parcela $x_{h i}$ está contribuindo para aumentar o índice de Gini.

Para uma parcela $x_{h i} \geq 0$ da renda $x_{i}$, define-se a medida de progressividade de Lerman-Yitzhaki como

$$
\pi_{h}=G-C_{h}
$$

Um tributo $\left(t_{i}\right)$ pode ser considerado uma parcela negativa da renda final, isto é,

$$
t_{i}=-x_{h i}
$$

A curva de concentração do tributo é construída usando os valores de $t_{i}$ e a respectiva razão de concentração pode ser obtida por meio de (10) ou (11). Note-se que 
nesta última expressão a troca de sinal de $x_{h i}$ não afeta o resultado, pois ocorre troca do sinal da covariância e de $\mu_{h}$.

De acordo com (14), um tributo contribui para reduzir a desigualdade se $C_{h}>G$, pois o respectivo $\varphi_{h}$ será negativo. Então, para incluir o caso dos tributos, a medida de progressividade de Lerman-Yitzhaki deve ser definida como

$$
\pi_{h}=\left(\operatorname{sinal} \operatorname{de} \varphi_{h}\right)\left(G-C_{h}\right)
$$

O nome dado a essa medida de progressividade é um reconhecimento do pioneirismo de Lerman e Yitzhaki (1985 e 1995), que ressaltaram a importância de considerar a ordenação das rendas finais e demonstraram que, dado um pequeno acréscimo proporcional em $x_{h i}$, isto é, multiplicando $x_{h i}$ por $1+\theta$, com $\theta$ arbitrariamente pequeno, a variação $\Delta G$ causada no índice de Gini é tal que

$$
\lim _{\theta \rightarrow 0} \frac{\Delta G}{\theta}=\varphi_{h}\left(C_{h}-G\right)=-\pi_{h}\left|\varphi_{h}\right|
$$

com $\left|\varphi_{h}\right|$ indicando o valor absoluto de $\varphi_{h}$.

Essa expressão mostra que a elasticidade de $G$ em relação a $x_{h i}$ é

$$
\varphi_{h}\left(\frac{C_{h}}{G}-1\right)=-\frac{\pi_{h}\left|\varphi_{h}\right|}{G}
$$

As expressões (18) e (19) mostram como o efeito de um pequeno acréscimo proporcional na parcela $x_{h i}$ sobre o índice de Gini depende do grau de progressividade da parcela e do valor absoluto da sua participação na renda total. Na realidade, são esses resultados que justificam considerar a expressão (17) como uma medida apropriada da progressividade da parcela $x_{h i}$.

Para ilustrar a decomposição do índice de Gini conforme (13) e a interpretação da medida de progressividade (17), será analisado um exemplo artificial muito simples, de uma sociedade com 2.000 pessoas, sendo 800 da categoria A e 1.200 da categoria B.

Há dois tipos de renda: 1 e 2. As pessoas da categoria A recebem $\$ 2.025$ por mês da renda tipo 1, e nenhuma renda tipo 2 . As pessoas da categoria $B$ não recebem nenhuma renda tipo 1 , mas recebem $\$ 450$ por mês da renda tipo 2 . As pessoas da categoria A estão em situação privilegiada, com uma renda mensal 4,5 vezes maior do que as pessoas da categoria B. Nesse exemplo artificial, as pessoas recebem apenas um dos dois tipos de renda. É óbvio que essa não é uma situação usual: no Brasil há domicílios cujo RDPC é formado exclusivamente por rendimento de aposentadorias, mas, na maioria dos domicílios com aposentados, a renda de aposentadorias é apenas uma fração da renda total.

Não se discute, aqui, se a diferença de renda entre as duas categorias é ou não justa. Para isso seria indispensável informar os critérios que definem quem faz parte de 
cada categoria. Mas aqui interessa analisar apenas como cada tipo de renda contribui para o valor do índice de Gini da desigualdade da distribuição da renda na sociedade toda.

A Tabela 1 mostra como a população e a renda dessa sociedade artificial estão divididas pelas duas categorias.

Tabela 1

A distribuição da renda em uma sociedade artificial com dois tipos de renda.

\begin{tabular}{l|r|r|r|r|r|r}
\hline \multirow{2}{*}{$\begin{array}{l}\text { Categoria de } \\
\text { pessoas }\end{array}$} & \multicolumn{2}{|c|}{ Pessoas } & \multicolumn{2}{c|}{ Renda mensal \$ } & \multicolumn{2}{c}{ Renda total } \\
\cline { 2 - 7 } & № & $\%$ & Tipo 1 & Tipo 2 & $\$ 1.000$ & $\%$ \\
\hline A & 800 & 40 & 2.025 & 0 & 1.620 & 75 \\
\hline B & 1.200 & 60 & 0 & 450 & 540 & 25 \\
\hline Total & 2.000 & 100 & & & 2.160 & 100 \\
\hline
\end{tabular}

Pode-se verificar que a renda média é $\mu=\$ 1.080$ e que o índice de Gini é $G=0,35$. Verifica-se, também, que $\mu_{1}=810, \mu_{2}=270, \varphi_{1}=0,75, \varphi_{2}=0,25, C_{1}=0,6$ e $C_{2}=-0,4$.

De acordo com a expressão (13), verifica-se que

$$
\varphi_{1} C_{1}+\varphi_{2} C_{2}=0,75 \cdot 0,6+0,25 \cdot(-0,4)=0,35=G
$$

A medida de progressividade para a renda tipo 1 é

$$
\pi_{1}=G-C_{1}=0,35-0,6=-0,25,
$$

mostrando que essa parcela é regressiva, contribuindo para aumentar a desigualdade. A medida de progressividade para a renda tipo 2 é

$$
\pi_{2}=G-C_{2}=0,35-(-0,4)=0,75,
$$

mostrando que essa parcela é progressiva.

Um aumento de $1 \%$ nas rendas tipo 1 faz com que o índice de Gini aumente para 0,3519 , que é, aproximadamente, a mudança prevista por meio de (18) para $\theta=0,01$.

Há artigos em que se procura avaliar a natureza regressiva ou progressiva de uma parcela da renda calculando o índice de Gini na situação hipotética em que essa parcela é eliminada. ${ }^{3}$ No exemplo artificial em análise, se fosse eliminada a renda tipo 1, as pessoas da categoria A ficariam com renda igual a zero, a renda média da sociedade cairia para \$270 e o índice de Gini aumentaria para 0,40. Pode-se dizer, então, que a inclusão da renda tipo 1 faz o índice de Gini diminuir de 0,40 para 0,35. Mas isso não permite concluir que a renda tipo 1 é progressiva, contribuindo para reduzir a desigualdade, pois a situação hipotética em que essa parcela da renda total é eliminada é irreal e inverte a posição relativa das duas categorias de pessoas. Simplesmente não é razoável considerar uma situação hipotética em que a maior parte da renda é "jogada fora". Economistas estão acostumados a analisar os efeitos de mudanças marginais. No caso do exemplo analisado,

(3) Ver IPEA (2008b). 
se a renda tipo 1 for reduzida de $1 \%$ para todas as pessoas que a recebem, o índice de Gini se reduz de aproximadamente 0,0019 , passando a ser $0,35-0,0019=0,3481$, mostrando a natureza regressiva dessa parcela da renda.

Outro erro metodológico consiste em avaliar a natureza progressiva ou regressiva de uma parcela calculando o índice de Gini apenas para as pessoas que recebem aquele tipo de renda. No exemplo artificial analisado, o índice de Gini da distribuição da renda entre pessoas da categoria A é igual a zero, mas não faz sentido concluir, a partir desse fato, que a renda tipo 1 contribui para reduzir a desigualdade.

\section{Análise dos dados da PNAD de 2007}

O rendimento domiciliar per capita (RDPC) é definido como a razão entre o rendimento domiciliar e o número de moradores, excluindo as pessoas cuja condição no domicílio é pensionista, empregado doméstico ou parente de empregado doméstico. São considerados apenas os domicílios particulares permanentes com declaração do rendimento domiciliar.

Antes de 2004, a PNAD não abrangia a área rural da antiga região Norte (RO, AC, AM, RR, PA e AP). Então, quando são feitas comparações ao longo do tempo, é necessário excluir, nas PNADs de 2004 em diante, os dados referentes a essa área rural. Como nesta seção são utilizadas somente as PNADs de 2006 e 2007, a análise é feita considerando os dados de todo o território nacional.

A Tabela 2 mostra diversas características da distribuição do RDPC no Brasil, em 2006 e 2007, de acordo com os dados da PNAD. Os valores de rendas de 2006 foram colocados na mesma unidade monetária de 2007, considerando, nos dois anos, a média geométrica do INPC de setembro e outubro (o que corresponde a centrar o deflator em primeiro de outubro). ${ }^{4}$

Chama a atenção a queda no valor do $5^{\circ}$ percentil, apesar do crescimento de $2,7 \%$ no rendimento per capita médio. Barros (2008) e Neri e Carvalhaes (2008) já assinalaram que, entre 2006 e 2007, a mudança na distribuição da renda foi desfavorável aos $10 \%$ mais pobres (especialmente para os $5 \%$ mais pobres), contrariando o que vinha ocorrendo desde 2001. A proporção do total de pessoas cujo RDPC declarado é igual a zero passa de $0,66 \%$ em 2006 para $1,17 \%$ em 2007.

Observa-se, na Tabela 2, que a proporção da renda total que fica com o décimo mais pobre cai de $0,94 \%$ em 2006 para $0,89 \%$ em 2007. A proporção da renda total apropriada pelos $20 \%$ mais pobres também se reduz um pouco, passando de $2,96 \%$ para $2,93 \%$. Mas a proporção da renda total correspondente à metade mais pobre da população sobe de $14,6 \%$ para $14,9 \%$ e diminui a proporção apropriada pelos $20 \%$ mais ricos ou por grupos menores da cauda direita da distribuição. Ocorre redução tanto no índice de Gini como na medida $\mathrm{T}$ de Theil.

(4) Os valores monetários de 2006 foram multiplicados por 1,048480. 
Tabela 2

A distribuição do RDPC no Brasil em 2006 e 2007.

\begin{tabular}{|c|c|c|c|}
\hline \multirow{2}{*}{ Estatística } & \multicolumn{2}{|c|}{ Ano } & \multirow{2}{*}{$\begin{array}{c}\text { Variação } \\
\%\end{array}$} \\
\hline & 2006 & 2007 & \\
\hline № de pessoas $(1.000)$ & 182.342 & 183.662 & 0,72 \\
\hline № de domicílios (1.000) & 53.455 & 54.841 & 2,6 \\
\hline Pessoas por domicílio & 3,41 & 3,35 & $-1,8$ \\
\hline RDPC médio ${ }^{(1)}$ & 513,8 & 527,8 & 2,7 \\
\hline Percentil $^{(1)} \quad 5^{o}$ & 52,4 & 51,4 & $-1,9$ \\
\hline $10^{\circ}$ & 81,3 & 83,2 & 2,3 \\
\hline $20^{\circ}$ & 125,3 & 129,8 & 3,6 \\
\hline $25^{\mathrm{o}}$ & 148,1 & 154,3 & 4,2 \\
\hline $40^{\circ}$ & 222,8 & 236,7 & 6,2 \\
\hline $50^{\circ}$ & 283,1 & 300,0 & 6,0 \\
\hline $60^{\circ}$ & 367,0 & 380,0 & 3,5 \\
\hline $75^{\circ}$ & 541,0 & 570,0 & 5,4 \\
\hline $80^{\circ}$ & 651,6 & 670,0 & 2,8 \\
\hline $90^{\circ}$ & $1.048,5$ & $1.100,0$ & 4,9 \\
\hline $95^{\mathrm{o}}$ & $1.698,5$ & $1.700,0$ & 0,09 \\
\hline $99^{\circ}$ & $3.984,2$ & $4.000,0$ & 0,4 \\
\hline \multicolumn{4}{|c|}{$\%$ da renda apropriada pelos } \\
\hline $10 \%$ mais pobres & 0,94 & 0,89 & \\
\hline $20 \%$ mais pobres & 2,96 & 2,93 & \\
\hline $40 \%$ mais pobres & 9,68 & 9,80 & \\
\hline $50 \%$ mais pobres & 14,6 & 14,9 & \\
\hline $20 \%$ mais ricos & 60,5 & 59,6 & \\
\hline $10 \%$ mais ricos & 44,5 & 43,6 & \\
\hline $5 \%$ mais ricos & 31,7 & 30,9 & \\
\hline $1 \%$ mais rico & 12,7 & 12,4 & \\
\hline Índice de Gini & 0,560 & 0,553 & \\
\hline T de Theil & 0,636 & 0,617 & \\
\hline
\end{tabular}

A seguir será analisada a contribuição de várias parcelas do rendimento domiciliar para o índice de Gini da distribuição do RDPC. Cabe ressaltar que na terminologia adotada pelo IBGE, denomina-se "rendimento do trabalho" o rendimento obtido por meio do exercício de uma atividade, como empregado (público ou privado), conta-própria ou empregador. Apesar da semelhança das expressões, não se deve confundir o "rendimento do trabalho" do IBGE com o conceito de "remuneração do trabalho" em teoria econômica.

O rendimento total (ou rendimento de todas as fontes), além do rendimento de todos os trabalhos, inclui aposentadorias, pensões, rendimentos de aluguéis, doações recebidas, juros, dividendos e transferências do governo, como as do programa Bolsa 
Família. Entre as aposentadorias e pensões, a PNAD permite distinguir as aposentadorias e pensões "oficiais" (recebidas de instituto de previdência ou do governo). ${ }^{5}$

A Tabela 3 mostra a decomposição do índice de Gini da distribuição do RDPC no Brasil em 2007, de acordo com a metodologia apresentada na seção anterior.

$\mathrm{Na}$ Tabela 3 há informações sobre nove parcelas mutuamente exclusivas do rendimento domiciliar, uma linha referente ao rendimento de todos os empregados (agregando militares, funcionários públicos estatutários e outros empregados) e um subtotal mais abrangente que inclui rendimento do trabalho de empregados, conta-própria e empregadores.

Tabela 3

Decomposição do RDPC e do correspondente índice de Gini, considerando 9 parcelas do rendimento domiciliar. Brasil, 2007

\begin{tabular}{|c|c|c|c|c|c|}
\hline \multirow[b]{2}{*}{ Parcela do rendimento } & \multirow{2}{*}{$\begin{array}{l}\text { Participação } \\
\qquad\left(\varphi_{h}\right)\end{array}$} & \multirow{2}{*}{$\begin{array}{c}\text { Razão de } \\
\text { concentração } \\
\left(C_{h}\right)\end{array}$} & \multicolumn{2}{|c|}{ Parcela de $G$} & \multirow{2}{*}{$\begin{array}{l}\text { Progressi- } \\
\text { vidade } \\
\left(G-C_{h}\right)\end{array}$} \\
\hline & & & $\varphi_{h} C_{h}$ & $\%$ & \\
\hline Rend. de todos os trabalhos & 0,7694 & 0,5577 & 0,4291 & 77,6 & $-0,0044$ \\
\hline Empregados $^{(1)}$ & 0,5135 & 0,5139 & 0,2639 & 47,7 & 0,0394 \\
\hline Militar e func. público ${ }^{(1)}$ & 0,1084 & 0,7443 & 0,0807 & 14,6 & $-0,1911$ \\
\hline Outros empregados ${ }^{(1)}$ & 0,4051 & 0,4522 & 0,1832 & 33,1 & 0,1011 \\
\hline Conta-própria $^{(1)}$ & 0,1554 & 0,5123 & 0,0796 & 14,4 & 0,0410 \\
\hline Empregador $^{(1)}$ & 0,1005 & 0,8515 & 0,0856 & 15,5 & $-0,2983$ \\
\hline Aposent. e pensões oficiais & 0,1791 & 0,5652 & 0,1012 & 18,3 & $-0,0119$ \\
\hline Outras aposent. e pensões & 0,0144 & 0,5516 & 0,0079 & 1,4 & 0,0017 \\
\hline Doações de outros domic. & 0,0054 & 0,4146 & 0,0022 & 0,4 & 0,1387 \\
\hline Renda de aluguéis & 0,0143 & 0,7837 & 0,0112 & 2,0 & $-0,2304$ \\
\hline $\begin{array}{l}\text { Juros, Bolsa Família e } \\
\text { outros }\end{array}$ & 0,0174 & 0,0890 & 0,0015 & 0,3 & 0,4643 \\
\hline Total & 1,0000 & 0,5533 & 0,5533 & 100,0 & - \\
\hline
\end{tabular}

${ }^{(1)}$ Rendimento de todos os trabalhos de pessoa do domicílio classificada nessa categoria de posição na ocupação.

O rendimento do trabalho de empregados é um pouco progressivo, fazendo com que sua participação no índice de Gini $(47,7 \%)$ seja menor do que sua participação na renda total $(51,4 \%)$. Entre as parcelas analisadas, o rendimento do trabalho de empregadores é a mais regressiva, fazendo com que sua contribuição para o índice de Gini $(15,5 \%)$ seja substancialmente maior do que sua participação na renda total (10,0\%). Outra parcela bastante regressiva, como esperado, é o rendimento de aluguéis. A parcela mais progressiva é a última, que mistura rendimentos regressivos, como juros e dividendos, e

(5) O rendimento de abono de permanência (variável V1264 da PNAD) é uma parcela desprezível que foi agregada ao item aqui denominado "outras aposentadorias e pensões". 
rendimentos claramente progressivos, como os provenientes de programas de transferência de renda, especialmente o Bolsa Família (ver Soares et al., 2007).

As aposentadorias e pensões oficiais são ligeiramente regressivas, com $G-C_{h}=-0,012$, fazendo com que sua participação no índice de Gini $(18,3 \%)$ seja maior do que sua participação na renda total (17,9\%). Dada a predominância das aposentadorias e pensões oficiais, quando se considera o agregado de aposentadorias e pensões, a razão de concentração é igual a 0,5642 , o que leva a uma medida de progressividade negativa $\left(G-C_{h}=-0,011\right)$, indicando o caráter regressivo da parcela, que corresponde a $19,3 \%$ da renda total declarada e contribui com $19,7 \%$ do índice de Gini.

Não é difícil, no computador, recalcular as principais características da distribuição do RDPC no Brasil anulando todos os rendimentos de aposentadorias e pensões oficiais. O valor médio do RDPC cai de $\mathrm{R} \$ 527,80$ para $\mathrm{R} \$ 433,30$, a proporção de pessoas com RDPC igual a zero aumenta de $1,17 \%$ para $6,61 \%$ e o índice de Gini passa de 0,5533 para 0,5966. De acordo com o que foi discutido no final da Seção 2, não tem sentido, com base nesses resultados, concluir que as aposentadorias e pensões oficiais contribuem para reduzir a desigualdade. Trata-se de uma simulação sem nenhuma correspondência com alguma modificação viável nas regras previdenciárias. Pode interessar, isso sim, saber o efeito que teria uma pequena redução proporcional em todas as aposentadorias e pensões oficiais. De acordo com a expressão (18), com $\theta<0$, esse efeito é proporcional à medida de progressividade $\pi_{h}=G-C_{h}$. Os dados da PNAD de 2007 indicam que essa medida de progressividade é negativa $\left(\pi_{h}=-0,012\right)$, ou seja, que uma pequena redução proporcional no valor de todas as aposentadorias e pensões oficiais causaria uma redução no índice de Gini da distribuição do RDPC no Brasil. ${ }^{6}$

Verifica-se que 34,9\% dos domicílios do país, com 33,0\% das pessoas, têm algum rendimento de aposentadoria ou pensão (oficial ou não). A distribuição do RDPC nessa parte da população apresenta média igual a $\mathrm{R} \$ 632,90$ (acima da média geral, que é $\mathrm{R} \$$ 527,80 ) e índice de Gini igual a 0,510 (substancialmente abaixo do valor referente a toda a população, que é 0,553). Por outro lado, em 65,1\% dos domicílios, com 67,0\% das pessoas, não há nenhuma pessoa recebendo aposentadoria ou pensão. Nessa parte da população, a média do RDPC é R \$ 476,10 e o índice de Gini é igual a 0,571. Conforme o que foi discutido no final da Seção 1, não tem sentido concluir, com base nesses resultados, que as aposentadorias e pensões contribuem para reduzir a desigualdade (considerando que a desigualdade é menor dentro do grupo que recebe aposentadorias e pensões). ${ }^{7}$ Cabe ressaltar que, quando a população é dividida em grupos, a desigualdade total depende da desigualdade dentro dos grupos, mas também é afetada pela desigualdade entre os grupos. ${ }^{8}$

(6) Contrariamente ao que se afirma em IPEA (2008b).

(7) Argumento usado em Dedecca et al. (2007).

(8) No caso do índice de Gini, ainda há uma parcela referente à superposição das distribuições referentes aos diferentes grupos. 


\section{Diferenças regionais e limitações dos dados}

É importante assinalar que a contribuição das parcelas analisadas para a determinação do índice de Gini da distribuição do RDPC pode variar substancialmente entre as regiões do Brasil, como mostra a Tabela $4 .^{9}$

\section{Tabela 4}

Decomposição do RDPC e do correspondente índice de Gini, considerando 9 parcelas do rendimento domiciliar, no Nordeste e no Estado de São Paulo, em 2007

\begin{tabular}{l|c|c|c|c|c|c}
\hline \multirow{2}{*}{ Parcela do rendimento } & \multicolumn{3}{|c|}{ Nordeste } & \multicolumn{3}{c}{ SP } \\
\cline { 2 - 7 } & $\varphi_{h}$ & $C_{h}$ & $\%$ de $G$ & $\varphi_{h}$ & $C_{h}$ & $\%$ de $G$ \\
\hline Rend. de todos os trabalhos & 0,7110 & 0,5804 & 73,2 & 0,8024 & 0,5021 & 80,4 \\
\hline Empregados $^{(1)}$ & 0,4702 & 0,5616 & 46,8 & 0,5592 & 0,4353 & 48,5 \\
\hline Militar e func. público $^{(1)}$ & 0,1254 & 0,8086 & 18,0 & 0,0813 & 0,6999 & 11,4 \\
\hline Outros empregados $^{(1)}$ & 0,3448 & 0,4718 & 28,8 & 0,4779 & 0,3902 & 37,2 \\
\hline Conta-própria $^{(1)}$ & 0,1624 & 0,4861 & 14,0 & 0,1421 & 0,5360 & 15,2 \\
\hline Empregador $^{(1)}$ & 0,0784 & 0,8880 & 12,3 & 0,1011 & 0,8245 & 16,6 \\
\hline Aposent. e pensões oficiais $^{\text {Outras aposent. e pensões }}$ & 0,2159 & 0,5960 & 22,8 & 0,1584 & 0,4961 & 15,7 \\
\hline Doações de outros domic. & 0,0147 & 0,6296 & 1,6 & 0,0139 & 0,4839 & 1,3 \\
\hline Renda de aluguéis & 0,0084 & 0,3827 & 0,6 & 0,0029 & 0,3141 & 0,2 \\
\hline Juros, Bolsa Família e & 0,0089 & 0,8235 & 1,3 & 0,0144 & 0,7395 & 2,1 \\
\hline outros & 0,0410 & 0,0698 & 0,5 & 0,0081 & 0,2063 & 0,3 \\
\hline Total & 1,0000 & 0,5641 & 100,0 & 1,0000 & 0,5014 & 100,0 \\
\hline (1)
\end{tabular}

(1) Rendimento de todos os trabalhos de pessoa do domicílio classificada nessa categoria de posição na ocupação.

Considere-se, inicialmente, o rendimento do trabalho de militares e funcionários públicos estatutários. No Brasil e em todas as regiões analisadas, trata-se de uma parcela regressiva, com razão de concentração substancialmente acima do índice de Gini, fazendo com que sua contribuição para a desigualdade seja maior do que sua participação na renda total. No Brasil, essa parcela está associada com 14,6\% do índice de Gini (ver Tabela 3), verificando-se que essa percentagem é $18,0 \%$ no Nordeste, atinge $24,1 \%$ no Centro-Oeste e é apenas $11,4 \%$ no Estado de São Paulo. Destacando os dados do Distrito Federal, verifica-se que essa parcela constitui $31,5 \%$ da renda total declarada e está associada com nada menos do que 38,9\% do índice de Gini dessa unidade da federação.

Já foi visto que, no Brasil, o rendimento de aposentadorias e pensões oficiais é ligeiramente regressivo, o que também é observado no Nordeste, no conjunto dos Estados de MG, ES e RJ, no Centro-Oeste e no Estado do Rio de Janeiro. No Estado de São Paulo e na região Sul, entretanto, essa parcela é ligeiramente progressiva, de acordo com os dados da PNAD de 2007. Sua contribuição para o índice de Gini é condicionada,

(9) Por limitação de espaço, são apresentados, na tabela, apenas os resultados para o Nordeste e o estado de São Paulo. Resultados completos para as demais regiões estão disponíveis com o autor. 
basicamente, pela sua participação na renda total, sendo relativamente baixa no CentroOeste $(13,1 \%)$ e no Estado de São Paulo (15,7\%), e bem mais elevada no Nordeste $(22,8 \%)$ e no Estado do Rio de Janeiro $(27,8 \%)$.

Para quem trabalha com dados estatísticos sobre renda das pessoas obtidos por meio de questionários, é óbvio que os resultados devem ser examinados tendo em vista as limitações dos dados. Há uma tendência geral de subdeclaração dos rendimentos, que provavelmente tende a ser maior para rendimentos elevados. Mas os rendimentos de pequenos agricultores familiares, que constituem uma categoria relativamente pobre, também devem estar bastante subestimados devido ao fato de o levantamento não levar em consideração o valor da produção para autoconsumo.

Devido a sua natureza "formal", o valor de aposentadorias e pensões oficiais deve estar mais bem informado do que o de vários outros rendimentos e é provável, então, que os dados da PNAD levem a superestimar a natureza regressiva das aposentadorias e pensões oficiais.

Analisando os dados do Censo Demográfico de 2000, verifica-se que são registrados rendimentos extremamente elevados, que não são captados na PNAD, e que a razão de concentração de aposentadorias e pensões fica abaixo do índice de Gini, indicando que essa parcela do RDPC é progressiva (Hoffmann; Ney, 2008). Mas, conforme os dados do Censo Demográfico de 2000, a razão de concentração de aposentadorias e pensões é substancialmente maior do que a razão de concentração dos salários (rendimento do trabalho de empregados), de maneira análoga ao que se observa na Tabela 3, indicando que a distribuição dos rendimentos previdenciários está reforçando a desigualdade existente no país.

A Pesquisa de Orçamentos Familiares (POF) de 2002-2003 é outra fonte de dados recentes sobre a distribuição da renda no Brasil. Em análise exaustiva desses dados, Silveira (2008) verifica que a parcela da renda familiar per capita decorrente de aposentadorias e pensões é ligeiramente progressiva $\left(\pi_{h}=0,0301\right)$. Combinando os dados da POF com informações sobre despesas do governo e estimativas do número de servidores públicos estaduais e municipais aposentados, ele calculou medidas de progressividade para os benefícios pagos pelo RGPS (Regime Geral da Previdência Social) e pelos RPPSs (Regimes Próprios de Previdência Social), constatando que os primeiros são claramente progressivos $\left(\pi_{h}=0,2403\right)$ e os últimos são claramente regressivos $\left(\pi_{h}=-0,2821\right)$. Tendo em vista que aposentadorias e pensões dos RPPSs estão diretamente relacionados com os salários obtidos no final da vida ativa, este último resultado é coerente com a regressividade do rendimento do trabalho de militares e funcionários públicos estatutários constatada na Tabela 3.

Embora os dados da PNAD indiquem que o rendimento de aposentadorias e pensões seja uma parcela levemente regressiva da distribuição do RDPC no Brasil, é provável que esse resultado seja afetado pelo fato de se tratar de um tipo de renda com grau de subdeclaração relativamente baixo. Levando em consideração dados de outras 
fontes, é razoável afirmar que a razão de concentração de aposentadorias e pensões é semelhante ao índice de Gini da distribuição do RDPC no Brasil. Mas isso já indica um grau de concentração muito elevado das aposentadorias e pensões, pois o RDPC inclui parcelas claramente regressivas, como os aluguéis e o rendimento de empregadores. É claro que a natureza pouco progressiva do rendimento de aposentadorias e pensões oficiais no Brasil se deve, em grande parte, à dualidade do sistema previdenciário, incluindo o RGPS e os RPPSs, com normas muito distintas.

\section{Mudanças de 2001 a 2007}

Nesta seção são utilizados dados das PNADs de 2001 a 2007 para examinar como as diversas parcelas do RDPC contribuem para as mudanças no índice de Gini nesse período. Uma vez que até 2003 não foram coletados dados na área rural da antiga região Norte, para manter a comparabilidade, os dados referentes a essa área foram excluídos das PNADs de 2004 em diante.

A Tabela 5 mostra a participação das nove parcelas analisadas (e de dois subtotais) na renda total declarada. As pequenas diferenças entre os valores apresentados na última coluna dessa tabela e os da primeira coluna da Tabela 3 se devem à exclusão dos dados da área rural de RO, AC, AM, RR, PA e AP.

Tabela 5

Participação $\left(\varphi_{h}\right)$ de cada parcela do rendimento domiciliar na renda total. Brasil ${ }^{(1)}, 2001-2007$

\begin{tabular}{|c|c|c|c|c|c|c|c|}
\hline Estatística & 2001 & 2002 & 2003 & 2004 & 2005 & 2006 & 2007 \\
\hline Renda de todos os trabalhos & 0,7794 & 0,7738 & 0,7667 & 0,7634 & 0,7591 & 0,7591 & 0,7692 \\
\hline Empregados $^{(2)}$ & 0,4974 & 0,4972 & 0,4920 & 0,4994 & 0,5004 & 0,4999 & 0,5142 \\
\hline Militar e func. público ${ }^{(2)}$ & 0,0997 & 0,0993 & 0,1002 & 0,1014 & 0,0986 & 0,1067 & 0,1088 \\
\hline Outros empregados ${ }^{(2)}$ & 0,3977 & 0,3979 & 0,3918 & 0,3979 & 0,4018 & 0,3932 & 0,4054 \\
\hline Conta-própria $^{(2)}$ & 0,1647 & 0,1575 & 0,1582 & 0,1521 & 0,1457 & 0,1400 & 0,1542 \\
\hline Empregador $^{(2)}$ & 0,1174 & 0,1190 & 0,1166 & 0,1120 & 0,1131 & 0,1193 & 0,1008 \\
\hline Aposent. e pensões oficiais & 0,1711 & 0,1722 & 0,1848 & 0,1813 & 0,1816 & 0,1798 & 0,1794 \\
\hline Outras aposent. e pensões & 0,0143 & 0,0144 & 0,0135 & 0,0147 & 0,0162 & 0,0152 & 0,0144 \\
\hline Doações de outros domic. & 0,0067 & 0,0076 & 0,0071 & 0,0073 & 0,0071 & 0,0071 & 0,0054 \\
\hline Renda de aluguéis & 0,0193 & 0,0191 & 0,0174 & 0,0174 & 0,0182 & 0,0173 & 0,0144 \\
\hline $\begin{array}{l}\text { Juros, Bolsa Família e } \\
\text { outros }^{(3)}\end{array}$ & 0,0091 & 0,0129 & 0,0105 & 0,0159 & 0,0177 & 0,0215 & 0,0172 \\
\hline Total & 1,0000 & 1,0000 & 1,0000 & 1,0000 & 1,0000 & 1,0000 & 1,0000 \\
\hline
\end{tabular}

A Tabela 6 mostra as razões de concentração de cada parcela ao longo do período analisado e, na última linha, o índice de Gini da distribuição do RDPC no país (exclusive a área rural da antiga região Norte). 
Tabela 6

Razões de concentração $\left(C_{h}\right)$ relativas ao índice de Gini da distribuição do rendimento domiciliar per capita. Brasil ${ }^{(1)}, 2001-2007$

\begin{tabular}{|c|c|c|c|c|c|c|c|}
\hline Estatística & 2001 & 2002 & 2003 & 2004 & 2005 & 2006 & 2007 \\
\hline Renda de todos os trabalhos & 0,5889 & 0,5834 & 0,5778 & 0,5668 & 0,5642 & 0,5631 & 0,5566 \\
\hline Empregados $^{(2)}$ & 0,5467 & 0,5441 & 0,5347 & 0,5227 & 0,5218 & 0,5149 & 0,5112 \\
\hline Militar e func. & 0,7387 & 0,7411 & 0,7331 & 0,7332 & 0,7355 & 0,7455 & 0,7430 \\
\hline Outros empregados $^{(2)}$ & 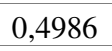 & 50 & & & 3 & 524 & 0,4490 \\
\hline Conta-própria $^{(2)}$ & 0,5232 & 0,5012 & 0,5043 & 0,4995 & 0,4863 & 0,4857 & 0,5156 \\
\hline Empregador $^{(2)}$ & & & & & & & 0,8508 \\
\hline Aposent. e pensõ & 0,6011 & 0,5929 & 0,5 & 0,5 & 0,5 & 0,5 & 0,5620 \\
\hline Outras aposent. e pensões & 0,6260 & 0,5870 & 0,5698 & 0,5678 & 0,6142 & 0,5814 & 0,5503 \\
\hline Doações de outros domic. & 0,3951 & 0,4294 & 0,4035 & 0,4625 & 0,4135 & 0,4422 & 0,4115 \\
\hline Renda de aluguéis & 0,7971 & 0,8030 & 0,8009 & 0,7863 & 0,7886 & 0,7904 & 0,7822 \\
\hline Juros, Bolsa Família e o & & 0,5122 & & & & & 0,0910 \\
\hline Índice de Gini & 0,5938 & 0,5872 & 0,5808 & 0,5687 & 0,5661 & 0,5593 & 0,5519 \\
\hline
\end{tabular}

(1) Exclusive as áreas rurais de RO, AC, AM, RR, PA e AP.

(2) Rendimento de todos os trabalhos de pessoa do domicílio classificada nessa categoria de posição na ocupação.

${ }^{(3)}$ Inclui outros programas de transferências do governo.

A mudança no valor do índice de Gini em determinado período pode ser associada às mudanças na participação $\left(\varphi_{h}\right)$ e na razão de concentração $\left(C_{h}\right)$ de cada parcela, com base na expressão (13). Uma exposição dessa metodologia de decomposição das mudanças ( $\Delta G$ ) no índice de Gini pode ser encontrada em Hoffmann (2007a) ou Hoffmann e Ney (2008). Denomina-se efeito-composição a parcela de $\Delta G$ que pode ser associada à mudança em $\varphi_{h}$ e denomina-se efeito-concentração a parcela de $\Delta G$ que pode ser associada à mudança em $C_{h}$.

A Tabela 7 mostra a contribuição de cada parcela da renda e os respectivos efeitocomposição e efeito-concentração, quando se comparam as distribuições do RDPC em 2001 e 2007, com todos os efeitos medidos como percentagem da redução do índice de Gini no período, que é $\Delta G=0,5519-0,5938=-0,0419$.

Considere-se, inicialmente, o rendimento do trabalho dos "outros empregados" (empregados do setor privado e todos os celetistas). Sua participação na renda total cresce de 39,77\% em 2001 para 40,54\% em 2007. Como sua razão de concentração é inferior ao índice de Gini, o crescimento de $\varphi_{h}$ contribui com 1,83\% da redução do índice de Gini. Mas, a contribuição principal dessa parcela se deve à substancial redução da razão de concentração (de 0,4986 em 2001 para 0,4490 em 2007) que, associada com a sua elevada participação $\left(\varphi_{h}\right)$ na renda total, leva a uma redução do índice de Gini que representa $47,55 \%$ da redução total observada. Assim, quase metade da redução do índice de Gini pode ser associada ao rendimento do trabalho dos "outros empregados". 
Tabela 7

Decomposição da mudança no índice de Gini $(\Delta G=-0,0419)$ da distribuição do RDPC no Brasil ${ }^{(1)}$ entre 2001 e 2007

\begin{tabular}{|c|c|c|c|}
\hline Parcela do RDPC & $\begin{array}{l}\text { Efeito total } \\
\% \text { de } \Delta G\end{array}$ & $\begin{array}{c}\text { Efeito- } \\
\text { concentração } \\
\% \text { de } \Delta G\end{array}$ & $\begin{array}{c}\text { Efeito- } \\
\text { composição } \\
\% \text { de } \Delta G\end{array}$ \\
\hline Renda de todos os trabalhos & 59,80 & 59,80 & 0,00 \\
\hline Empregados $^{(2)}$ & 44,65 & 42,88 & 1,76 \\
\hline Militar e func. público ${ }^{(2)}$ & $-4,73$ & $-1,08$ & $-3,65$ \\
\hline Outros empregados $^{(2)}$ & 49,38 & 47,55 & 1,83 \\
\hline Conta-própria $^{(2)}$ & 1,57 & 2,90 & $-1,33$ \\
\hline Empregador $^{(2)}$ & 13,59 & 2,37 & 11,22 \\
\hline Aposent. e pensões oficiais & 16,20 & 16,37 & $-0,17$ \\
\hline Outras aposent. e pensões & 2,59 & 2,59 & $-0,01$ \\
\hline Doações de outros domic. & $-0,77$ & $-0,24$ & $-0,53$ \\
\hline Renda de aluguéis & 3,14 & 0,60 & 2,54 \\
\hline Juros, Bolsa Família e outros & 19,04 & 14,09 & 4,95 \\
\hline $\operatorname{Total}^{(3)}$ & 100,00 & 85,16 & 14,84 \\
\hline
\end{tabular}

${ }^{(1)}$ Exclusive as áreas rurais de RO, AC, AM, RR, PA e AP.

(2) Rendimento de todos os trabalhos de pessoa do domicílio classificada nessa categoria de posição na ocupação.

(3) Considerando a divisão do RDPC em 9 parcelas. Considerando apenas 6 parcelas, o efeito-concentração é $93,22 \%$ e o efeito-composição é $6,78 \%$.

Como outro exemplo, considere-se a última parcela, formada por juros, Bolsa Família e outros rendimentos. Sua participação $\left(\varphi_{h}\right)$ na renda total é pequena, crescendo de $0,91 \%$ em 2001 para $1,72 \%$ em 2007. Como sua razão de concentração é menor do que o índice de Gini, isso contribui para reduzir a desigualdade geral (4,95\% de $\Delta G$ ). Mas o efeito-concentração é mais forte $(14,09 \%$ de $\Delta G)$, uma vez que ocorre uma extraordinária redução da razão de concentração dessa parcela (de 0,5394 em 2001 para apenas 0,0910 em 2007), associada à expansão do programa Bolsa Família no período. Assim, apesar de sua reduzida participação na renda total, essa parcela está associada a 19,04\% da redução do índice de Gini entre 2001 e 2007.

No caso das aposentadorias e pensões oficiais, a participação $\left(\varphi_{h}\right)$ dessa parcela fica um pouco acima do valor de $G$, o crescimento de $\varphi_{h}$ contribui para aumentar ligeiramente o índice de Gini $(-0,17 \%$ do $\Delta G=-0,0419)$. Como a razão de concentração dessa parcela diminui de 0,6011 para 0,5620 , há um efeito-concentração que representa $16,37 \%$ de $\Delta G$. Embora nos dois anos a razão de concentração das aposentadorias e pensões oficiais seja maior do que $G$, indicando que, de acordo com os dados da PNAD, trata-se de uma parcela regressiva da renda domiciliar per capita, no período 2001-2007 essa parcela responde por $16,20 \%$ da queda observada no índice de Gini.

É importante não confundir a natureza progressiva ou regressiva de uma parcela da renda com o sinal de sua contribuição para a mudança no valor do índice de Gini em 
determinado período. Tanto parcelas regressivas como parcelas progressivas podem sofrer alterações que contribuem para aumentar ou para reduzir a desigualdade. O rendimento dos empregadores, que é a mais regressiva das parcelas analisadas, contribui para a redução do índice de Gini no período 2001-2007, principalmente devido à redução de sua participação na renda total (efeito-composição).

Na Tabela 8, a decomposição da mudança no índice de Gini é feita considerando dois períodos: 2001-2004 e 2004-2007. No primeiro período, $\Delta G=0,5687-0,5938=-0,0251$ e no segundo período, $\Delta G=0,5519-0,5687=-0,0168$.

\section{Tabela 8}

Decomposição da mudança no índice de Gini da distribuição do RDPC no Brasil ${ }^{(1)}$ nos períodos 2001-2004 e 2004-2007

\begin{tabular}{|c|c|c|c|c|c|c|}
\hline \multirow{3}{*}{ Parcela do RDPC } & \multicolumn{3}{|c|}{$\begin{array}{c}\text { Período 2001-2004 } \\
\Delta G=-0,0251\end{array}$} & \multicolumn{3}{|c|}{$\begin{array}{c}\text { Período 2004-2007 } \\
\Delta G=-0,0168\end{array}$} \\
\hline & \multirow{2}{*}{$\begin{array}{c}\text { Efeito } \\
\text { total } \\
\% \text { de } \Delta G\end{array}$} & \multirow{2}{*}{$\begin{array}{c}\text { Efeito- } \\
\text { concentraçãoc } \\
\% \text { de } \Delta G\end{array}$} & \begin{tabular}{|c|} 
Efeito- \\
composição
\end{tabular} & \multirow{2}{*}{$\begin{array}{c}\text { Efeito } \\
\text { total } \\
\% \text { de } \Delta G\end{array}$} & \multirow{2}{*}{$\begin{array}{c}\text { Efeito- } \\
\text { concentração } \\
\% \text { de } \Delta G\end{array}$} & \multirow{2}{*}{$\begin{array}{c}\text { Efeito- } \\
\text { composição } \\
\text { \% de } \Delta G\end{array}$} \\
\hline & & & $\%$ de $\Delta G$ & & & \\
\hline Renda de todos os trabalhos & 67,91 & 68,13 & $-0,22$ & 46,47 & 46,51 & $-0,05$ \\
\hline Empregados $^{(2)}$ & 48,16 & 47,79 & 0,37 & 38,40 & 34,57 & 3,83 \\
\hline Militar e func. público ${ }^{(2)}$ & 1,12 & 2,20 & $-1,08$ & $-13,93$ & $-6,15$ & $-7,78$ \\
\hline Outros empregados ${ }^{(2)}$ & 47,04 & 46,94 & 0,09 & 52,33 & 47,82 & 4,51 \\
\hline Conta-própria ${ }^{(2)}$ & 11,45 & 14,97 & $-3,51$ & $-13,98$ & $-14,67$ & 0,69 \\
\hline Empregador $^{(2)}$ & 8,30 & 2,33 & 5,97 & 22,05 & 2,54 & 19,51 \\
\hline Aposent. e pensões oficiais & 2,64 & 3,34 & $-0,71$ & 37,09 & 36,88 & 0,21 \\
\hline Outras aposent. e pensões & 3,34 & 3,37 & $-0,03$ & 1,51 & 1,51 & 0,00 \\
\hline Doações de outros domic. & $-1,52$ & $-1,89$ & 0,37 & 0,52 & 1,94 & $-1,42$ \\
\hline Renda de aluguéis & 2,39 & 0,79 & 1,60 & 4,39 & 0,39 & 4,00 \\
\hline Juros, Bolsa Família e outros & 25,24 & 18,97 & 6,27 & 10,02 & 6,74 & 3,28 \\
\hline Total $^{(3)}$ & 100,00 & 91,02 & 8,98 & 100,00 & 77,01 & 22,99 \\
\hline
\end{tabular}

(1) Exclusive as áreas rurais de RO, AC, AM, RR, PA e AP.

${ }^{(2)}$ Rendimento de todos os trabalhos de pessoa do domicílio classificada nessa categoria de posição na ocupação.

(3) Considerando a divisão do RDPC em 9 parcelas. Considerando apenas 6 parcelas, o efeitoconcentração é $92,71 \%$ no primeiro período e $93,98 \%$ no segundo período e o efeito-composição é $7,29 \%$ no primeiro período e $6,02 \%$ no segundo período.

São observadas mudanças importantes na contribuição das diferentes parcelas para a redução do índice de Gini nos dois períodos.

A mudança associada às aposentadorias e pensões oficiais é pequena no período 2001-2004 e se torna substancial no período 2004-2007, quando a respectiva razão de concentração diminui de 0,5964 para 0,5620 .

A contribuição da parcela que inclui juros e Bolsa Família é superior a $25 \%$ de $\Delta G$ no primeiro período e igual a apenas $10 \%$ no segundo período. 
No caso do rendimento do trabalho dos conta-própria, o efeito-concentração contribui para reduzir o índice de Gini no período 2001-2004 (14,97\% de $\Delta G$ ), mas está associado a um aumento do índice de Gini no período 2004-2007 (-14,67\% de $\Delta G$ ). Note-se, na Tabela 6, que a razão de concentração dessa parcela cai de 0,5232 em 2001 para 0,4857 em 2006, mas cresce abruptamente para 0,5156 em 2007.

Entre as 9 parcelas da divisão inicial do RDPC, aquela com maior efeito sobre o índice de Gini é o rendimento do trabalho dos "outros empregados" (empregados do setor privado e todos os celetistas), correspondendo a $47,04 \%$ de $\Delta G$ no primeiro período e a $52,33 \%$ de $\Delta G$ no segundo período.

Em geral, o efeito-concentração é bem maior do que o efeito-composição. Ocorre o oposto no caso do rendimento do trabalho de empregadores, cuja razão de concentração permanece entre 0,85 e 0,86 em todo o período analisado. Como se trata de uma parcela com razão de concentração muito maior do que o índice de Gini, sua contribuição para a redução da desigualdade se deve à diminuição de sua participação na renda total, que cai de $11,74 \%$ em 2001 para 11,20\% em 2004 e para 10,08\% em 2007 (ver Tabela 5).

\section{Principais conclusões}

a) Para uma parcela positiva da renda per capita, a diferença entre o índice de Gini global e a razão de concentração da parcela $\left(\pi_{h}=G-C_{h}\right)$ é uma medida apropriada de sua progressividade, indicando o sinal e a intensidade do efeito, sobre o índice de Gini, de um pequeno acréscimo proporcional em todos os valores dessa parcela.

b) Em todo o período analisado, de acordo com os dados da PNAD, a razão de concentração de aposentadorias e pensões oficiais fica um pouco acima do índice de Gini, indicando o caráter regressivo dessa parcela do RDPC no Brasil.

c) Há substanciais diferenças regionais na contribuição de diferentes parcelas do rendimento domiciliar para o índice de Gini $(G)$ da distribuição do RDPC. O rendimento do trabalho de militares e funcionários públicos estatutários, por exemplo, está associado a $11,4 \%$ de $G$ no Estado de São Paulo, mas essa percentagem é 38,9\% no Distrito Federal. Aposentadorias e pensões oficiais respondem por $15,7 \%$ de $G$ no Estado de São Paulo e por $27,8 \%$ de $G$ no Rio de Janeiro.

d) Provavelmente os dados da PNAD levam a superestimar a regressividade de aposentadorias e pensões, por serem menos subdeclaradas do que outras parcelas do rendimento domiciliar. A análise de outras informações (incluindo o Censo Demográfico de 2000 e a POF de 2002-2003) permite afirmar que aposentadorias e pensões oficiais não contribuem, como poderiam, para minorar o elevado grau de desigualdade da distribuição da renda no país, basicamente devido à dualidade do sistema previdenciário, com normas especiais para os militares e funcionários públicos estatutários.

e) O fato de o índice de Gini da distribuição observada ser menor do que o índice de Gini de uma distribuição hipotética em que são eliminadas as aposentadorias e pensões não permite concluir que essa parcela da renda é progressiva. 
f) $\mathrm{O}$ fato de o índice de Gini da distribuição do RDPC em toda a população ser maior do que o índice de Gini da distribuição do RDPC considerando apenas domicílios que recebem aposentadorias ou pensões também não permite concluir que essa parcela é progressiva.

g) Entre as nove parcelas do RDPC analisadas, a que mais contribui para a redução da desigualdade no período 2001-2007 é o rendimento dos empregados do setor privado (incluindo todos os celetistas), representando quase 50\% da redução do índice de Gini no período.

h) A contribuição das mudanças no rendimento de aposentadorias e pensões oficiais para reduzir a desigualdade é pequena no período 2001-2004 $(2,6 \%$ de $\Delta G=-0,0251)$, mas se torna substancial no período 2004-2007 (37,1\% de $\Delta G=-0,0168)$.

i) A contribuição das alterações na parcela que inclui o Bolsa Família alcança $25,2 \%$ da redução do índice de Gini no período 2001-2004, mas se reduz a $10,0 \%$ de $\Delta G$ no período 2004-2007.

\section{Referências bibliográficas}

BARROS, Ricardo Paes de. Resultados de pesquisa divulgados em reportagem de Fernando Dantas intitulada "Renda dos mais pobres cresce abaixo da média da população". O Estado de São Paulo, 2 nov. 2008, p. B10.

; FOGUEL, Miguel Nathan; ULYSSEA, Gabriel (Org.). Desigualdade de renda no Brasil: uma análise da queda recente. Brasília: IPEA, 2006, 2007. 2 v.

DEDECCA, Cláudio Salvadori; BALLINI, Rosângela; MAIA, Alexandre Gori. Rendimentos previdenciários e distribuição de renda. In: FAGNANI, E.; POCHMANN, M. (Org.). Debates contemporâneos: economia social e do trabalho, n. 1: Mercado de trabalho, relações sindicais, pobreza e ajuste fiscal. São Paulo, LTr, 2007. p. 172-179.

FERREIRA, Carlos Roberto. Aposentadorias e distribuição da renda no Brasil: uma nota sobre o período 1981 a 2001. Revista Brasileira de Economia, v. 60, n. 3, p. 247-260, jul./set. 2006.

HOFFMANN, Rodolfo. Inequality in Brazil: the contribution of pensions. Revista Brasileira de Economia, v. 57, n. 4, p. 755-773, out./dez. 2003.

. Transferência de renda e redução da desigualdade no Brasil e em cinco regiões,

entre 1997 e 2005. In: BARROS, R. P.; FOGUEL, M. N.; ULYSSEA, G. (Org.). Desigualdade de renda no Brasil: uma análise da queda recente. Brasília: IPEA, 2007a. v. 2, p. 17-40.

Desigualdade de renda no Brasil em 2005 e sua decomposição. In: ANÁLISE da Pesquisa Nacional por Amostra de Domicílios - PNAD 2005. Livro 3: Pobreza e Desigualdade. Brasília: CGEE, 2007b. p. 157-183. (Centro de Gestão e Estudos Estratégicos), em CD.

; LEONE, Eugênia Troncoso. Participação da mulher no mercado de trabalho e desigualdade da renda domiciliar per capita no Brasil: 1981-2002. Nova Economia, Belo Horizonte, v. 14, n. 2, p. 35-58, maio/ago. 2004. 
HOFFMANN, Rodolfo; NEY, Marlon Gomes. A recente queda da desigualdade de renda no Brasil: análise de dados da PNAD, do Censo Demográfico e das Contas Nacionais. Econômica, Rio de Janeiro, v. 10, n. 1, p. 7-39, jun. 2008.

IPEA. Comunicado da Presidência n. 9. PNAD 2007: primeiras análises. 2008a. v. 1: Pobreza e mudança social. Disponível em: <www.ipea.gov.br $>$.

Comunicado da Presidência n. 10. PNAD 2007: primeiras análises. 2008b. v. 2: Mercado de trabalho, trabalho infantil, previdência. Disponível em: $<$ www.ipea.gov.br>.

NERI, Marcelo; CARVALHAES, Luisa. Será esta década a da igualdade? Conjuntura Econômica, v. 62, n. 10, p. 48-51, out. 2008.

NICHOLSON, Brian. A previdência injusta: como o fim dos privilégios pode mudar o Brasil. São Paulo: Geração Editorial, 2007.

SILVEIRA, Fernando Gaiger. Tributação, previdência e assistência sociais: impactos distributivos. 2008. 149p. Tese (Doutorado em Economia Aplicada)-Universidade Estadual de Campinas (UNICAMP), Campinas, 2008.

SOARES, Fábio Veras; SOARES, Sergei S. D.; MEDEIROS, Marcelo; OSÓRIO, Rafael G. Programas de transferência de renda no Brasil: impactos sobre a desigualdade. In: BARROS, R. P.; FOGUEL, M. N.; ULYSSEA, G. (Org.). Desigualdade de renda no Brasil: uma análise da queda recente. Brasília: IPEA, 2007. v. 2, p. 87-129. 